\title{
Reversible abnormalities of the Hering Breuer reflex in acrylamide neuropathy
}

\author{
PAUL SATCHELL \\ From the Department of Medicine, University of Sydney, Sydney, Australia
}

SUMMARY The sensitivity of the Hering Breuer reflex was compared in anaesthetised rabbits before, during and after the induction of acrylamide neuropathy, and was measured as the tracheal pressure which produced 30 seconds of apnoea. After four weeks of acrylamide (400 $\mathrm{mg} / \mathrm{kg}$ total dose) there was ataxia and the conduction velocity of hindlimb motor nerves was significantly reduced. At this time there was a marked and reproducible reduction in the sensitivity of the Hering Breuer reflex. The ataxia resolved within a month of stopping acrylamide administration. Three months after the cessation of acrylamide the sensitivity of the Hering Breuer reflex had increased significantly but had not returned to normal.

The mixed nerve conduction velocity of the thoracic vagus is reduced in dogs with acrylamide neuropathy,' and this reduction is due to failure of impulse conduction in the fastest conducting nerve fibres. ${ }^{2}$ In these animals there are also abnormalities in the baroreceptor control of heart rate and blood pressure consistent with damage to cardiopulmonary baroreceptors. ${ }^{3}$ It is likely that the impairment of impulse propagation in the fastest conducting vagal nerve fibres and the baroreceptor reflex abnormalities are causally related. The fastest conducting vagal nerve fibres also innervate lung stretch receptors as well as cardiopulmonary baroreceptors ${ }^{4}$ and lung inflation reflexes, which are dependent upon these receptors, should be damaged in acrylamide neuropathy.

The Hering Breuer lung inflation reflex is the inhibition of inspiration and the promotion of expiration by lung inflation. ${ }^{5}$ Slowly adapting lung stretch receptors play an important part in this reflex. ${ }^{6}$ The presence of an abnormal lung inflation reflex in animals with acrylamide neuropathy would imply that the myelinated nerve fibres innervating slowly adapting lung stretch receptors were damaged. In the present study, the inhibition of inspiration produced by lung inflation was used as a measure of the sensitivity of the Hering Breuer reflex. ${ }^{7-10}$ The aim of the study was to determine if the Hering

Address for reprint requests: Gordon Craig Laboratory, Department of Surgery, University of Sydney, Sydney 2006, Australia.

Received 26 October 1984. Accepted 5 December 1984
Breuer reflex was reversibly damaged in acrylamide neuropathy by comparing the degree of inspiratory inhibition before, during and after rabbits had developed neuropathy.

\section{Methods}

\section{Animals}

Mixed strain rabbits, weighing 2.8 to $4.4 \mathrm{~kg}$,.were given acrylamide twice a week as a subcutaneous injection. The acrylamide was dissolved in saline and a total dose of 400 $\mathrm{mg} / \mathrm{kg}$ was achieved over a period of four weeks. Control animals, housed under the same conditions, were given saline alone.

Estimation of the strength of the Hering Breuer reflex All animals were anaesthetised with intravenous pentobarbitone $(30 \mathrm{mg} / \mathrm{kg})$ and intubated. The endotracheal tube was connected to a T-tube. A pilot study suggested that the simplest way of obtaining reproducible volume changes independant of the stage of the respiratory cycle was to pass a constant flow of gas over the opening of the stem of the T-tube, the pressure being set by a resistance piece attached to the outlet arm of the T-tube. Oxygen from a constant high pressure source was passed through a high resistance valve, producing a constant flow into the inlet arm of the T-tube. A range of resistance pieces could be attached to the outlet arm of the $T$-tube, raised the pressure in the T-tube and endotracheal tube by reproducible amounts. The percentage of carbon dioxide in the expired air was measured (Datex CO101) by sampling at the junction of the endotracheal tube and the T-tube. The tracheal pressure was also measured (Sanborn 267B Manometer).

After a supplemental dose of anaesthetic had been given, a bead electrode was passed under the xiphisternal 
Table 1 Motor conduction velocity studies in rabbits with acrylamide neuropathy*

\begin{tabular}{|c|c|c|c|c|c|c|c|c|c|c|c|c|c|}
\hline & \multicolumn{7}{|c|}{ Sciatic-tibial } & \multicolumn{6}{|c|}{ Popliteal-tibial } \\
\hline & \multirow[t]{2}{*}{$\begin{array}{l}\text { Animal } \\
\text { number }\end{array}$} & \multicolumn{3}{|c|}{$\begin{array}{l}\text { Before } \\
\text { acrylamide }\end{array}$} & \multicolumn{3}{|c|}{$\begin{array}{l}\text { After } \\
\text { acrylamide }\end{array}$} & \multicolumn{3}{|c|}{$\begin{array}{l}\text { Before } \\
\text { acrylamide }\end{array}$} & \multicolumn{3}{|c|}{$\begin{array}{l}\text { After } \\
\text { acrylamide }\end{array}$} \\
\hline & & Range & Mean & $S D$ & Range & Mean & $S D$ & Range & Mean & $S D$ & Range & Mean & $S D$ \\
\hline $\begin{array}{l}\text { Control } \\
\text { Treated }\end{array}$ & $\begin{array}{l}4 \\
5\end{array}$ & $\begin{array}{l}56-66 \\
50-63\end{array}$ & $\begin{array}{l}59 \\
56\end{array}$ & $\begin{array}{l}5 \\
5\end{array}$ & $\begin{array}{l}55-65 \\
46-59\end{array}$ & $\begin{array}{l}61 \\
51 \dagger\end{array}$ & $\begin{array}{l}4 \\
5\end{array}$ & $\begin{array}{l}46-56 \\
45-57\end{array}$ & $\begin{array}{l}50 \\
51\end{array}$ & $\begin{array}{l}5 \\
5\end{array}$ & $\begin{array}{l}51-55 \\
39-51\end{array}$ & $\begin{array}{l}52 \\
44 \dagger\end{array}$ & $\begin{array}{l}2 \\
4\end{array}$ \\
\hline
\end{tabular}

*All values of MCV in metres/second.

tp $<0.005$, paired $t$ test.

cartilage to record the diaphragmatic EMG. At this stage the expired percentage of carbon dioxide was between 6.5 and $7.5 \%$. The condition of the animal was allowed to stabilise for 15 to 20 minutes. Different outflow resistances were placed on the T-tube outlet during expiration. At this time, the expired percentage of carbon dioxide was between 5.0 and $6.5 \%$. An outflow resistance was found which consistently produced 30 seconds of apnoea. The tracheal pressure which produced 30 seconds of apnoea (P30) was used as a measure of the sensitivity of the Hering Breuer reflex. ${ }^{7}$ Apnoea was limited to 30 seconds because asphyxial death can occur in the rabbit.' In each animal multiple estimates of the P30 were determined and a mean value obtained.

The duration of apnoea at other tracheal pressures was measured. An inhibitory ratio, another measure of the sensitivity of the Hering Breuer reflex, was also determined. This inhibitory ratio was similar to other inhibitory ratios or apnoeic indexes. ${ }^{7-10}$ The ratio was determined by comparing the duration of apnoea, the time interval from the pressure increase to the onset of phrenic nerve activity, with the time interval between breaths before tracheal pressure was increased. Mean values were again obtained.

Nine rabbits were studied before and after four weeks of acrylamide administration. Four control animals were studied simultaneously in an identical manner. Three of the treated animals were reexamined 3 months after the cessation of acrylamide. When a study was repeated in an animal, the P30 was measured only when the expired percentage of carbon dioxide was identical to that of previous studies in that particular animal. Tracheal pressure, heart rate and the diaphragmatic EMG were recorded on a Grass Polygraph.

\section{Hindlimb electrophysiology and histology}

Motor conduction velocity for the sciatic-tibial and popliteal-tibial nerves was determined in five affected and four control animals. Techniques, which have been described previously, were used with minor modifications." ${ }^{11}$ These included: (a) the latency and interelectrode distance measurements were performed in triplicate, the stimulating electrodes being withdrawn between determinations, (b) the compound muscle action potential recordings were stored on computer (PDP11/40) and latencies were measured with a computer generated cursor, (c) the leg skin temperature of each animal at successive studies was matched exactly using a water filled heating blanket which surrounded the leg and thorax.

Rabbit hindlimb nerves were fixed by perfusion and myelinated fibres were counted using methods described previously.

\section{Results}

\section{Peripheral neuropathy}

The only clinical abnormality in rabbits after 4 weeks of acrylamide administration was ataxia. The motor conduction velocity (MCV) in the sciatictibial nerve and the popliteal-tibial nerve was significantly reduced (paired $t$ test, $\mathrm{p}<0.005$ ) (table 1). Swollen and occasional degenerating nerve fibres were observed in hindlimb nerves. The myelinated fibre diameter distribution was not appreciably different in the treated animals (fig 1). Ataxia resolved within 2 to 3 weeks after the cessation of acrylamide.

\section{Lung inflation reflex}

When tracheal pressure was increased by attaching a resistance to the outflow arm of the $T$-tube, the resulting lung inflation inhibited phasic diaphragmatic activity (fig. 2A). The tracheal pressure required to produce 30 seconds of apnoea (P30) in normal animals varied very little from study to study. The maximum difference within any animal was $2 \mathrm{~mm}$ $\mathrm{Hg}$, even when animals were examined repeatedly for periods as long as six months. In nine normal animals, prior to acrylamide administration, the maximum difference in the P30 between animals was $3 \mathrm{~mm} \mathrm{Hg}$; the $\mathrm{P} 30$ ranged from 3 to $6 \mathrm{~mm} \mathrm{Hg}$ (mean, 4; SD, 0.4) (table 2).

After four weeks of acrylamide administration, animals no longer became apnoeic when tracheal pressure was increased. The respiratory rate, the phrenic neurogram and the change in tracheal pressure with each breath were little altered by lung inflation (fig 2B). Substantially higher tracheal pressures were required to produce prolonged apnoea. At 4 weeks the P30 ranged from 10 to $14 \mathrm{~mm} \mathrm{Hg}$ (mean, 11; SD, 0.4), which was significantly increased (paired $t$ test, $\mathrm{p}<0.001$ ) (table 2).

Two of the nine animals with neuropathy were used for morphological studies. In these two ani- 

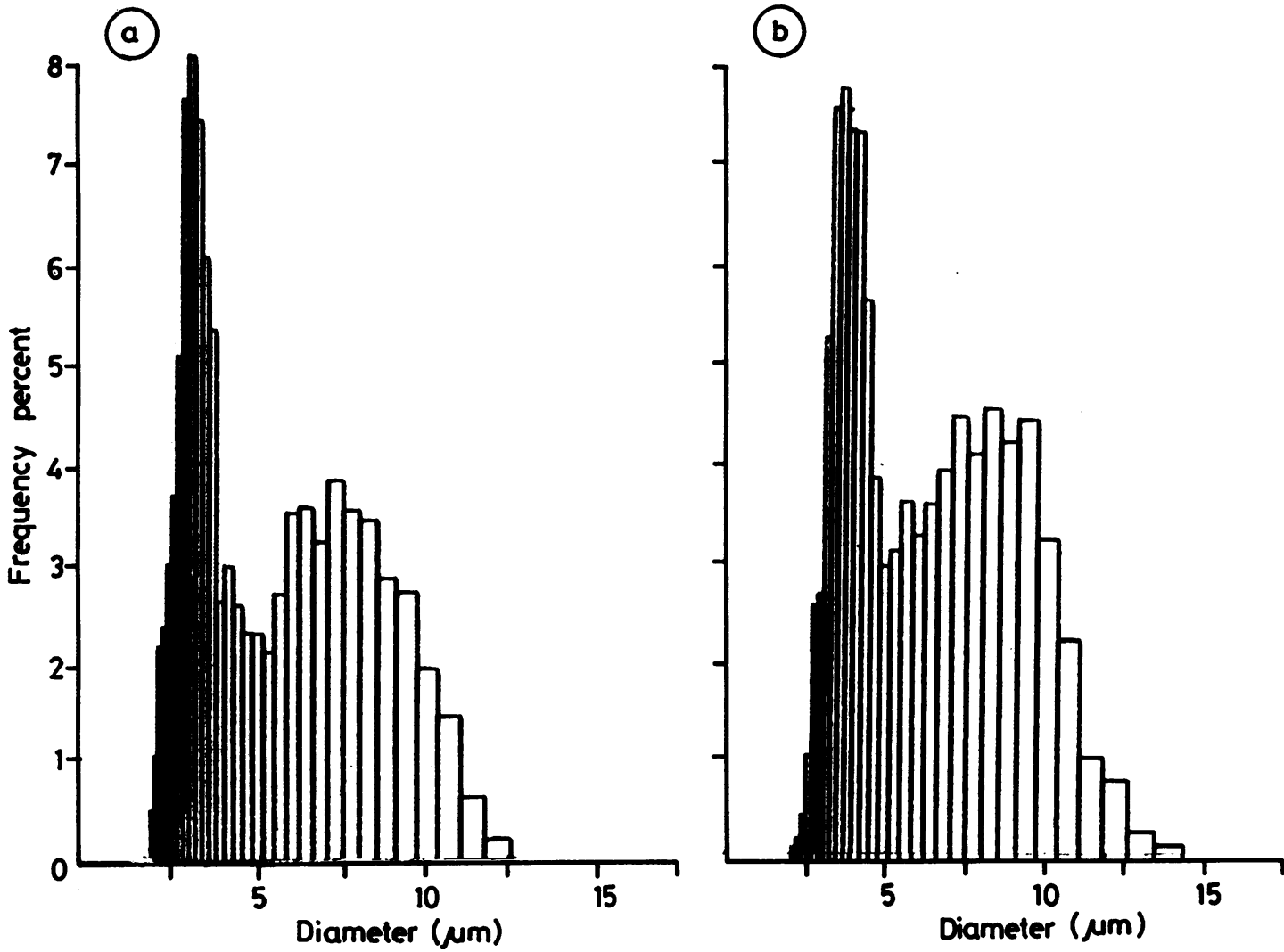

Fig 1 Diameter distribution of myelinated nerve fibres in the posterior tibial nerve in a control $(A)$ and an acrylamide treated rabbit $(B)$ after four weeks of subcutaneous acrylamide (total dose $400 \mathrm{mg} / \mathrm{kg}$ ). The differences observed do not suggest that there is a loss of large myelinated fibres in the treated animal.

mals, and in two animals from the pilot study, there was no evidence of pneumonia after the cessation of acrylamide administration. Four out of the remaining seven affected animals died of pneumonia within seven days of their second anaesthetic. Control animals never succumbed to repeated episodes of anaesthesia. In the three animals that recovered, the P30 had not returned to the original value three months after the cessation of acrylamide (table 2).

The inhibitory ratio was determined at various tracheal pressures in all animals. The relationship between tracheal pressure and the inhibitory ratio changed markedly in the animals with acrylamide neuropathy, there being no overlap in the ranges of ratio values before and after the administration of the neurotoxin (fig 3 ). In the three animals that recovered, the inhibitory ratios at three months after stopping acrylamide administration were outside the range of values obtained when the animals were ataxic but had not returned to the range of values observed in normal animals (fig 3). At this time, the Hering Breuer reflex was still abnormal, although the ataxia had resolved at least two months previously.

\section{Discussion}

The present study has demonstrated that the sensitivity of the Hering Breuer reflex declined significantly when rabbits developed acrylamide neuropathy and increased after the cessation of acrylamide administration.

The method used to measure the sensitivity of the Hering Breuer reflex had several deficiences. Methods which rely upon the inhibition of inspiration produced by lung inflation cannot measure differences in inspiratory force nor can they assess the expiratory activating component of the reflex.' However, these methods have advantages of non invasiveness and simplicity, essential features in a 


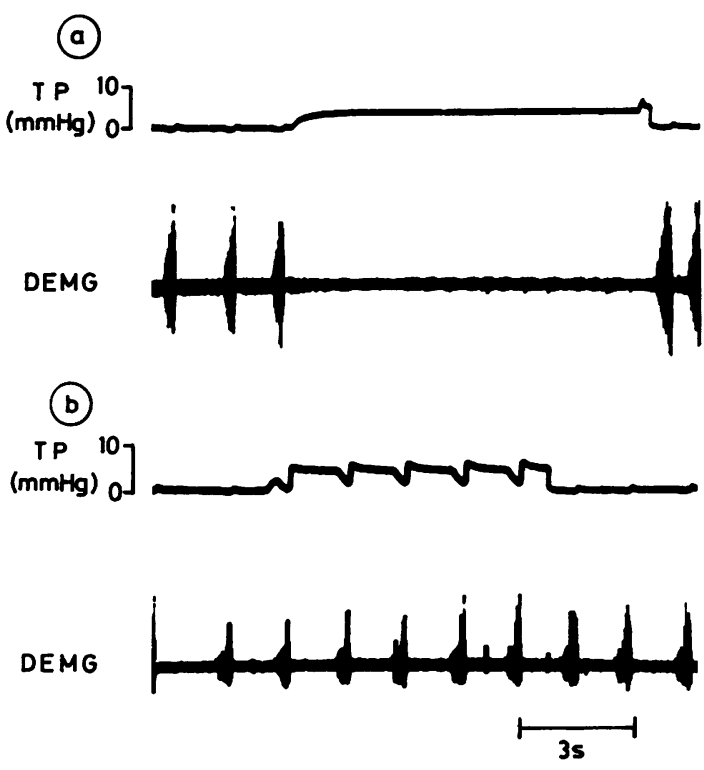

Fig 2 The effect of lung inflation on the diaphragmatic $E M G$ before $(A)$ and after $(B)$ acrylamide administration in a rabbit. Upper trace; tracheal pressure: lower trace; diaphragmatic EMG. Acrylamide has abolished the inhibition of respiration produced by lung inflation.

study involving repetitive experiments on rabbits with evolving neuropathy. Anaesthesia also affects the measurement of the sensitivity of the Hering Breuer reflex. ${ }^{10}$ In the present study, the level of chemoreceptor drive was not precisely controlled in the comparison between animals. The sensitivity of the Hering Breuer reflex is affected by the prevailing chemoreceptor drive, being increased when peripheral chemoreceptor effects are abolished. ${ }^{10} \mathrm{~A}$ systematic effect on the results was unlikely, as vari-

Table 2 Pressure required to produce 30 seconds of apnoea

\begin{tabular}{|c|c|c|c|}
\hline Animal & $\begin{array}{l}\text { Before } \\
\text { acrylamide } \\
\text { (mm Hg) }\end{array}$ & $\begin{array}{l}\text { After } \\
\text { acrylamide } \\
\text { (mm Hg) }\end{array}$ & $\begin{array}{l}\text { Three months } \\
\text { after } \\
\text { acrylamide } \\
(\mathrm{mm} \mathrm{Hg})\end{array}$ \\
\hline $\begin{array}{l}5 \\
7 \\
8 \\
11 \\
12 \\
14 \\
15 \\
16 \\
17 \\
\text { Mean } \\
\text { SD }\end{array}$ & $\begin{array}{l}3 \\
4 \\
3 \\
4 \\
3 \\
5 \\
5 \\
6 \\
4 \\
4 \\
0 \cdot 4\end{array}$ & $\begin{array}{l}12 \\
11 \\
10 \\
11 \\
11 \\
10 \\
13 \\
14 \\
10 \\
11^{*} \\
0.4\end{array}$ & $\begin{array}{l}\frac{5}{-} \\
= \\
- \\
8 \\
\frac{8}{-}\end{array}$ \\
\hline
\end{tabular}

${ }^{*} \mathrm{p}<0.001$ paired $t$ test.

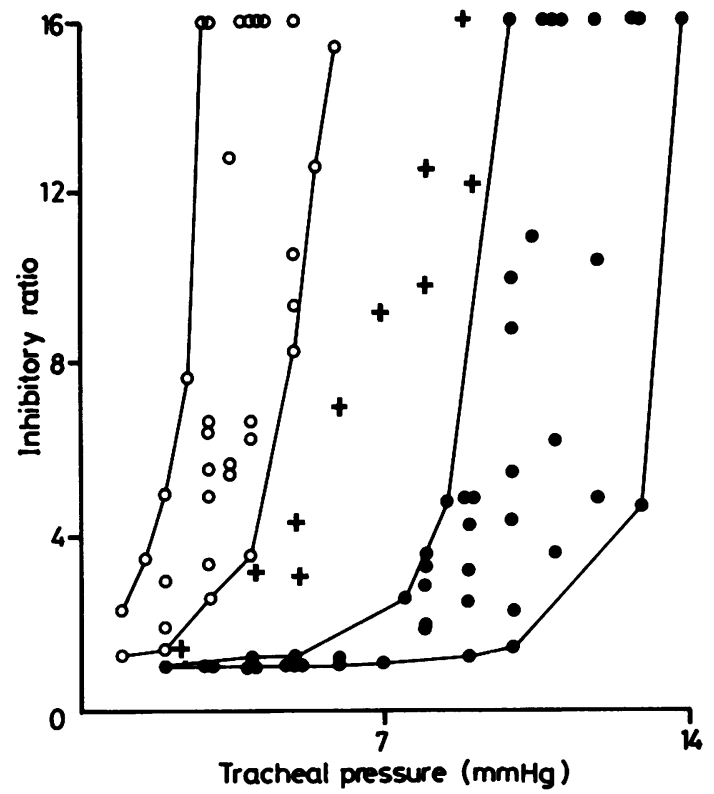

Fig 3 The relationship between the inhibitory ratio and tracheal pressure in nine rabbits before (open circle) and after (closed circle) acrylamide administration. The areas between the lines represent the ranges for the control and treated conditions. Three animals recovered. Their ratio values (crosses), 3 months after the cessation of acrylamide, lie outside the control and treated ranges.

ations in chemoreceptor drive were reduced by ventilating with pure oxygen, and were strictly controlled for the comparison within each animal.

In the present study, the fluctuation in the sensitivity of the Hering Breuer reflex was most simply explained as being due to damage to nerve fibres innervating slowly adapting lung stretch receptors, the receptors most important for this reflex. ${ }^{6}$ The results were also consistent with damage to the receptors themselves. There are several observations from studies on the acrylamide affected dog that support this explanation. ${ }^{1312}$ In acrylamide neuropathy, the fastest conducting vagal nerve fibres are damaged ${ }^{\prime}$ and it is this type of nerve fibre that innervates slowly adapting lung stretch receptors. ${ }^{4}$ As well, there are degenerating myelinated nerve fibres in the thoracic vagal trunk. ${ }^{1}$ Tonic vagal afferent nerve activity, which is dominated by cardiorespiratory rhythms in normal animals, ${ }^{6}$ is absent in animals with acrylamide neuropathy. ${ }^{12}$ This lack of respiratory related nerve activity suggests that at eupnoeic lung volumes there might be little or no nerve activity in fibres innervating slowly adapting lung stretch receptors. 
There is also a reduction in the sensitivity of the Hering Breuer reflex in rabbits exposed to sulphur dioxide. ${ }^{9}$ This reflex abnormality is associated with significant alterations in the discharge characteristics of slowly adapting lung stretch receptors, while there are only small alterations in the firing properties of lung irritant receptors. ${ }^{13}$ The findings from animals exposed to sulphur dioxide support the suggestion that the reduction in the sensitivity of the Hering Breuer reflex in animals with acrylamide neuropathy was due to dysfunction of slowly adapting lung stretch receptors and their innervating nerve fibres.

The innervation of the lung is damaged in different ways in sulphur dioxide exposed animals and animals with acrylamide neuropathy. Sulphur dioxide is thought only to affect slowly adapting lung stretch receptors. The distal parts of nerve fibres innervating receptors, as well as the receptors themselves are affected in acrylamide neuropathy. ${ }^{14}$ Thus, damage to both muscle spindles and to their IA nerve fibres have been demonstrated electrophysiologically. ${ }^{1516}$ In a study on the innervation of the oesophagus in dogs with acrylamide neuropathy, there appeared to be a group of nerve fibres innervating slowly adapting mechanoreceptors that were not conducting, as well as nerve fibres that were innervating abnormal receptors. ${ }^{12}$ The changes in sulphur dioxide exposed and acrylamide affected rabbits may be different in other respects. The incidence of pneumonia in the neuropathic group, after anaesthesia and intubation, suggested that receptors subserving the cough reflex might also have been damaged.

In the peripheral nervous system, acrylamide affects the distal parts of long, large diameter sensory and motor fibres as well as various types of receptor. ${ }^{1417}$ There might have been other parts of the nervous system, important for the Hering Breuer reflex, that were affected. Thus, dysfunction of phrenic nerve endings was possible but this would appear as a reduction in the amplitude of the phrenic electromyogram rather than the loss of the inhibitory effects of lung inflation. Because the neuropathy was mild it was unlikely that the short intercostal nerves, responsible for proprioceptive chest wall reflexes, would have been affected.

The consequences in man of a slowly evolving decline in the sensitivity of the Hering Breuer reflex in the presence of a developing distal axonopathy cannot be predicted from the present study. There are large species differences in the sensitivity of the Hering Breuer reflex.? The use of an anaesthetic and the lack of information concerning the expiratory activating component of the reflex are other reasons for being cautious about the implications of the present work. A study which is examining lung inflation reflexes in conscious dogs with a chronic side-hole tracheostomy will be more useful in this regard. ${ }^{18}$

This work was supported by a grant from the National Health and Medical Research Council of Australia and was carried out in the Gordon Craig Laboratory, Department of Surgery, University of Sydney. Helpful comments were made by Prof $J$ McLeod, Prof T Sears, Dr P Kirkwood, and Dr M Hersch.

\section{References}

' Satchell PM, McLeod JG, Harper B, Goodman AH. Abnormalities in the vagus nerve in canine acrylamide neuropathy. J Neurol Neurosurg Psychiatry 1982; 45:609-19.

${ }^{2}$ Hopkins AP, Gilliatt RW. Motor and sensory conduction velocity in the baboon: Normal values and changes during acrylamide neuropathy. $J$ Neurol Neurosurg Psychiatry 1971;34:415-26.

${ }^{3}$ Satchell PM. Circulatory control in canine acrylamide neuropathy. J Auton Nerv Syst 1984;10:93-106.

4 Paintal AS. The conduction velocities of respiratory and cardiovascular afferent fibres in the vagus nerve. $J$ Physiol (Lond) 1953;121:341-59.

${ }^{5}$ Hering E. Die Selbsteuerung der Atmung durch den Nervus Vagus. S. B. Akad. Wiss. Wein. 1868; 57:672-77. Translation by Ullman E. In: Porter E. ed. Breathing: Hering-Breuer Centenary Symposium. London: Churchill, 1970:360-1.

- Adrian ED. Afferent impulses in the vagus and their effect on respiration. J Physiol (Lond). 1933; 79:332-58.

7 Widdicombe JG. Respiratory reflexes in man and other mammalian species. Clin Sci 1961;21:163-70.

${ }^{8} \mathrm{Guz}$ A, Noble MIM, Trenchard D, Cochrane HL, Makey AR. Studies on the vagus nerves in man: their role in respiratory and circulatory control. Clin Sci 1964;27:293-304.

' Davies A, Dixon M, Penman R, Widdicombe JG, Wise JCM. Effect of repeated exposures to high concentrations of sulphur dioxide on respiratory reflexes in rabbits. Bull Eur Physiopathol Respir 1978;14:41-52.

${ }^{10}$ Bouverot P, Crance JP, Dejours P. Factors influencing the intensity of the Breuer-Hering inspirationinhibiting reflex. Respir Physiol 1970;8:376-84.

"Antony JH, Pollard JD, McLeod JG. Effects of plasmapheresis on the course of experimental allergic neuritis in rabbits. J Neurol Neurosurg Psychiatry 1981;44:1124-8.

${ }^{12}$ Satchell PM, McLeod JG. Abnormalities of oesophageal mechanoreceptors in canine acrylamide neuropathy. $J$ Neurol Neurosurg Psychiatry 1984;47:692-8.

${ }^{13}$ Davies A, Dixon M, Callanan D, Huszczuk A, Widdicombe JG, Wise JCM. Lung reflexes in rabbits during pulmonary stretch receptor blockade by sulphur dioxide. Respir Physiol 1978;34:83-101. 
${ }^{14}$ Schaumburg HH, Wisniewski H, Spencer PS. Ultrastructural studies of the dying back process. 1. Peripheral nerve terminal and axon degeneration in systemic acrylamide intoxication. J Neuropathol Exp Neurol 1974;33:260-84.

is Sumner AJ, Asbury AK. Physiological studies of the dying-back phenomenon. Muscle stretch afferents in acrylamide neuropathy. Brain 1975;98:91-100.

${ }^{16}$ Lowndes HE, Baker T, Michelson LP, Vincent-Ablazey M. Attenuated dynamic responses of primary endings of muscle spindles: a basis for depressed tendon responses in acrylamide neuropathy. Ann Neurol 1978;3:433-7.

${ }^{17}$ Spencer PS, Schaumburg HH. Classification of neurotoxic disease: a morphological approach. In: Spencer PS, Schaumburg HH, eds. Experimental and Clinical Neurotoxicology. Baltimore: WilliamsWilkins, 1980:92-99.

${ }^{18}$ Hersch MI, McLeod JG, Satchell PM, Sullivan CE. Abnormal respiratory reflexes and pulmonary slowly adapting receptors in acrylamide neuropathy. Proc Aust Physiol Pharmacol Soc 1984;15:155P. 